\title{
Biostatistics of fall armyworm Spodoptera frugiperda in maize plants in Bogor, West Java, Indonesia
}

\author{
WANDA RUSSIANZI, RULY ANWAR", HERMANU TRIWIDODO \\ Department of Plant Protection, Faculty of Agriculture, Institut Pertanian Bogor. Jl. Meranti, Kampus IPB Darmaga, Bogor 16680, West Java, Indonesia. \\ Tel.: +62-251-8629354, Fax.: +62-251-8629352, ‘email: ranwar@apps.ipb.ac.id \\ Manuscript received: 25 February 2021. Revision accepted: 29 May 2021.
}

\begin{abstract}
Russianzi W, Anwar R, Triwidodo H. 2021. Biostatistics of fall armyworm Spodoptera frugiperda in maize plants in Bogor, West Java, Indonesia. Biodiversitas 22: 3463-3469. Fall Armyworm (FAW) Spodoptera frugiperda (J.E. Smith) is an invasive species that has become important pest of maize in Indonesia since 2019. This research was aimed to study the biology and demographic statistics of FAW in maize at Bogor. Daily observations of 132 FAW individuals from egg to death were carried out as the basis for compiling biology and life table. The demographic statistics of FAW were calculated using the Jackknife approach from the basic life table data. ImagoFAW actives at night. Mating activity occurs between $06.00 \mathrm{pm}-04.00 \mathrm{am}$, while egg-laying activity occurs between $06.00 \mathrm{pm}-10.00 \mathrm{pm}$. Most hatching occurs between $00.00 \mathrm{am}-02.00 \mathrm{am}$. FAW has 6 larvae instars and there is no difference in stage between larvae that develop into male and female, which is around 15 days. The male pupae stage was longer than the female pupae, $8.78 \pm 0.12$ days and $7.81 \pm 0.15$ days. Male and female imagoes have the same life cycle, which is about 10 days. The life cycle of FAW was $32.26 \pm 0.41$ days, with a preoviposition period of $2.56 \pm 0.45$ days. Fecundity of FAW reaches $1012.62 \pm 99.12$ eggs per female imago. The population of FAW in Bogor has an intrinsic growth rate of $0.154 \pm 0.001$ individuals/day, with gross reproduction rate of $0.154 \pm 0.001$ individuals per generation, and net reproduction rate of $104.781 \pm 0.155$ individuals per imago per generation and a generation time of $30.114 \pm 0.002$ days.
\end{abstract}

Keywords: Invasive species, Jackknife, life table, maize pest

\section{INTRODUCTION}

The Fall Armyworm (FAW), Spodoptera frugiperda (J.E. Smith) (Lepidoptera: Noctuidae) is an important pest in maize that has resulted in considerable yield losses in many countries. Based on a survey conducted by CABI (2017), the loss of maize yields due to FAW attacks in Ghaza were $45 \%$ and $40 \%$ respectively. The damage of FAW in Africa reached 8.3 to 20.6 million tons with loss of 2.5 to 6.2 billion USD. This loss occurs due to proper FAW control methods (Day et al. 2017; FAO 2020).

FAW is a polyphagous insect pest native to tropical and subtropical Central America, which comes from the southern United States to northern Argentina. FAW has a wide host range of 353 plants from 76 families, especially Poaceae, Asteraceae, and Fabaceae. Furthermore, maize, rice, sorghum, cotton, grasses, and sugarcane have strong preferences (Montezano et al. 2018). Imago of FAW has strong flight and spreading out over long distances capability in the summer (Sparks 1979). In addition, factors that influence the distribution and abundance of $S$. frugiperda are human activities in the form of transportation or movement of plant material from one location to the next (Wang et al. 2020a). In 20016, FAW was discovered outside his native region in West Africa and Central Africa (Goergen et al. 2016). After that, FAW was reported spread to eastward and become invasive in the Sub-Saharan region (2008), Middle East and South Asia (2018), Mainland Asia, East Asia, Southeast Asia
(2019), and Australia (2020) (FAO 2020 ). FAW consists of two invasive sub-species, corn strains and rice strains. Corn-strain are mostly found in maize and sorghum, while rice strains prefer grasses (Nagoshi and Meagher 2004).

In Indonesia, FAW was first reported in March 2019 at West Sumatra. In Java Island, FAW was first reported attacking maize crops in Banten and Bogor in June 2019. FAW is reportedly found in almost all maize production centers in Indonesia in 2020. FAW collected from Banten confirmed classified Rice Strain after molecular identification using phylogenetic analysis (Sartiami et al. 2020). In 2019 FAW also reportedly attacked in Bandung, Garut, and Sumedang. The population that is still low is found in Bandung and Garut while the population already high is in Sumedang (Maharani et al. 2019). This research was aimed to study the biology and demographic statistics of FAW in maize at Bogor, West Java, Indonesia.

\section{MATERIALS AND METHODS}

\section{Preparation of feed plant}

Three seeds of maize were planted per planting hole at a distance of $20 \mathrm{~cm} \times 20 \mathrm{~cm}^{2}$. The seeds were planted once every three days to ensure that maize plants are always available for insect feed. Maize plants that used for insect feed are three to four weeks after planting (WAP). 


\section{Insect rearing}

Insect rearing was initiated by collecting or taking $S$. frugiperda larvae from maize plant fields in the Bogor area. The insects obtained with various larval stages were taken and put into a container $(40 \mathrm{~cm} \times 25 \mathrm{~cm} \times 7 \mathrm{~cm})$ to be reared in the laboratory. The larvae collected from the field are put in a plastic container until they become pupae.

The moths were paired between males and females with a sex ratio of 3:6 in a special container for their mating and laying their eggs. Three WAP maize plants were placed in a plastic container and infested with $S$. frugiperda imago. The eggs obtained will be hatched and reared with the previous following methods. This rearing method is found after searching for the best way for UGF growth, after examining the weaknesses of the existing cohort maintenance methods. One of them is the success of mating, producing fertile eggs due to mating, successful pupation, providing fresh and abundant food for the larvae, etc.

\section{Rearing of the cohort}

The life table of the cohort is a life table that follows the development of the cohort starting from $1^{\text {st }}$ instar larvae to the last surviving imago (Birch 1948). A cohort population is a number of individuals who have the same age (Begon et al. 2008). The reared cohort is used to study FAW biology and construct life table. The reared cohort begins by placing both male and female pupae in special cages. The container used allows the imago to mate and lay eggs.

There was a total of 11 egg groups were reared separately in hatchery containers (Figure 1). The hatchery container has $5.5 \mathrm{~cm}$ upper diameter, $4.0 \mathrm{~cm}$ bottom diameter, and $3.0 \mathrm{~cm}$ height (Figure 1a). The egg group was observed until the last eggs hatched. Each early instar larvae was recorded for the number and time of hatching. A total of $1321^{\text {st }}$ instar larvae will be used for the next rearing.

All of the first instar larvae are reared in a distinctive container filled with maize plants as a source of food. The special container for larvae has $8.0 \mathrm{~cm}$ upper diameter, 5.0 $\mathrm{cm}$ bottom diameter and $23.0 \mathrm{~cm}$ height (Figure $1 \mathrm{~b}$ ). Observations were made daily to determine larvae's growth, which included life larvae, dead larvae, molting process, and availability of the food. The final instar larvae were immediately transferred to the pupae container with $8.0 \mathrm{~cm}$ upper diameter, $5.5 \mathrm{~cm}$ bottom diameter, and 18.0 $\mathrm{cm}$ height (Figure 1c). The pupa container was filled with sterilized sawdust. The pupae that have been formed are immediately sorted and separated between male and female pupae. A total of 42 female pupae and 49 male pupae were paired and put in the imago container that has $6.5 \mathrm{~cm}$ upper diameter, $5.0 \mathrm{~cm}$ bottom diameter, $32.0 \mathrm{~cm}$ height (Figure 1d). That container were filled with maize plants and honey. The honey has been diluted with sterile water. The concentration of the honey solution is $10 \%$ and soaked to the cotton that hung in the cage. The soaked cotton was used as a source of nutrition for imago. Observations were made until the female in container died.

\section{Biology of fall armyworm}

The biological observations of FAW were carried out simultaneously with cohort insect rearing. Observation of cohort rearing was egg stage, larvae, pupae, male, female, sex ratio, pre-oviposition period, and daily fecundity of female imago. The life cycle of $S$. frugiperda was observed from the first instar larva being infested in maize plants until adult stage. Observation data were arranged in the biological table of $S$. frugiperda.
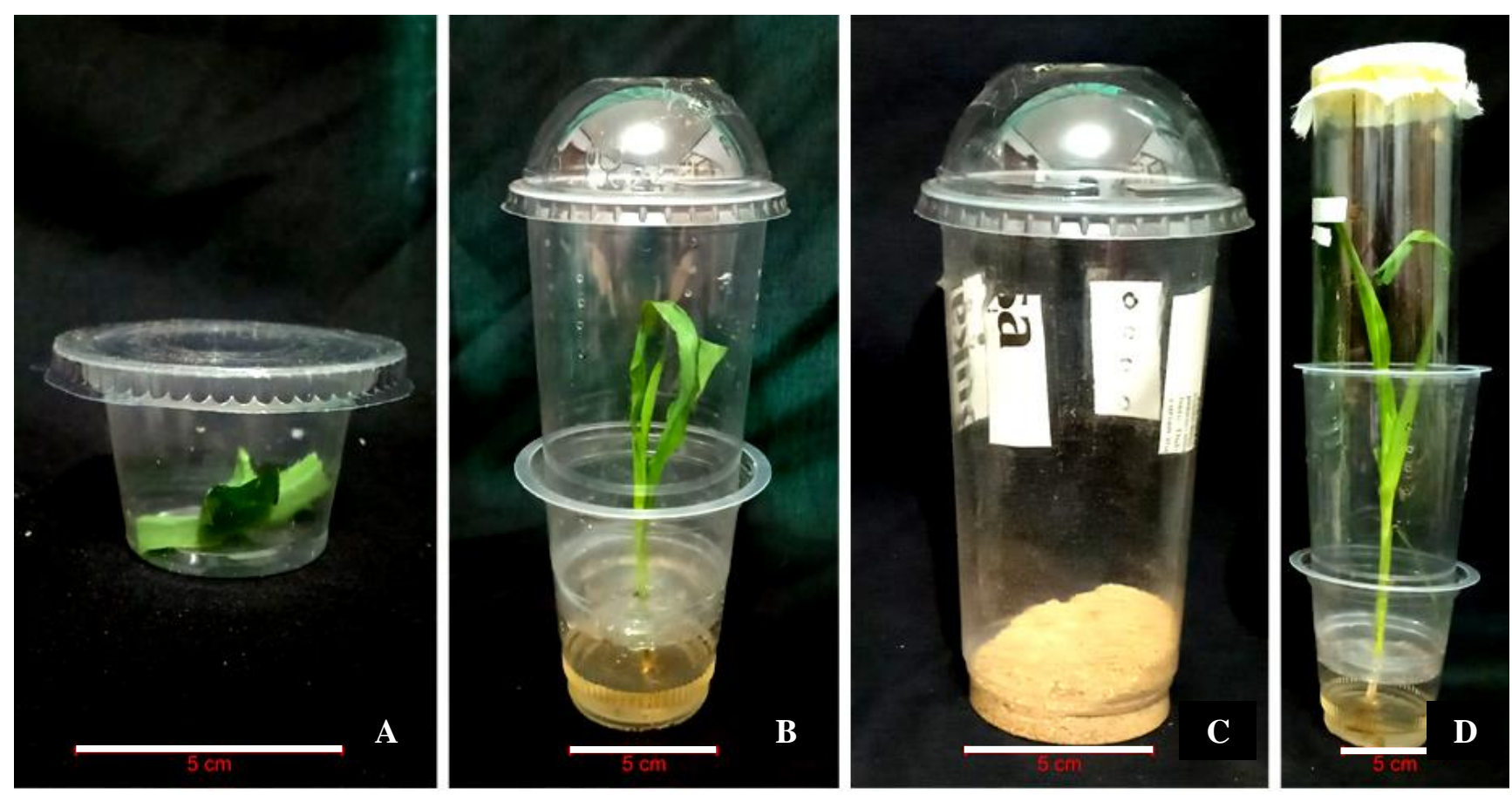

Figure 1. The S. frugiperda rearing container used for: A. Eggs, B. Larvae, C. Pupae, D. Imago. Bar $=5 \mathrm{~cm}$ 


\section{Life table and population parameters of fall armyworm}

Based on the results of cohort observations, data were arranged using a life table of FAW that consisting of median age (pivotal age, $x$ ), age-specific survival rate (lx), and age-specific fecundity (mx). Observation of agespecific survival rate (lx) was carried out by counting the number of $S$. frugiperda individuals living each day. Agespecific fecundity $(\mathrm{mx})$ is the average number of $S$. frugiperda larvae laid by imago every day at age (x). Agespecific survival rate and age-specific fecundity data can be described in the form of a curve and life table.

The cohort observation data were compiled in a life table. Determination of other demographic parameters can be determined by using life table data of $S$. frugiperda. According to Birch (1948), the calculated demographic parameters include:

Net Reproduction Rate $(\mathrm{Ro})=\sum 1_{\mathrm{x}} \mathrm{m}_{\mathrm{x}}$

Gross Reproduction Rate $(\mathrm{GRR})=\sum \mathrm{m}_{\mathrm{x}}$

Intrinsic Rate of Increase $(r)=\sum 1_{x} m_{x} e^{-r x}=1$, with initial $\mathrm{r}=\sum \ln \left(\mathrm{R}_{0}\right) / \mathrm{T}$

Generation Time Average $(\mathrm{T})=\ln \left(\mathrm{R}_{0}\right) / \mathrm{r}$, with initial $\mathrm{T}=\sum \mathrm{xl}_{\mathrm{x}} \mathrm{m}_{\mathrm{x}} / \sum \mathrm{l}_{\mathrm{x}} \mathrm{m}_{\mathrm{x}}$

Doubling Time $(\mathrm{DT})=\ln (2) / \mathrm{r}$

The calculation of the median value and diversity of demographic statistics made using the Jackknife method. Jackknife is used in statistics inferencing to estimate the bias and standard error of a statistic. A random sample from observations is used to calculate standard bias and error. The basic idea of The jackknife estimator is doing a count by eliminating one or some observations from a set example. Resampling process is done by discarding one observation over and over again (Efron 1982). Thus, through this approach will get 132 demographic statistics values and calculated the mean value and variety.

\section{Data analysis}

Observation and research data were processed using Microsoft Excel 2016, Statistical Analysis System (SAS) version 9.1, and the Minitab 16 program for t-test $(\alpha=5 \%)$

\section{RESULTS AND DISCUSSION}

The insect used in this observation was confirmed as $S$. frugiperda from the characteristics of $S$. frugiperda larva. The larva has a line on the head forming Y letter and there are dots on the last segment abdomen which form a thick and trapezoidal rectangle (Figure 3) correspond to Sartiami et al. (2020). The eggs laid by $S$. frugiperda in group like pearls covered with scales gave moldy appearance. The function of the scales function is to maintain the temperature. The new oviposited eggs have white color like a pearl and laying in group. Medium age has some eggs darker, blackish in color, and all-black color when the egg hatch immediately (figure 2).

There are six instars of $S$. frugiperda larvae in its life cycle. The $1^{\text {st }}$ instar has $\pm 0.82 \mathrm{~mm}$ length and transparent in color. The $2^{\text {nd }}$ instar larvae are started to turn green and have $\pm 6.384 \mathrm{~mm}$ in length (Figure 3 ). Larvae $3^{\text {rd }}$ to $5^{\text {th }}$ instar are actively eating stages, causing a lot of damage to maize plants. The $6^{\text {th }}$ instar larva has darker color with more vivid complexion on the body. This instar larva is not actively eating and will shrink in size to become prepupae. The $6^{\text {th }}$ instar larva will drop off from the leaf into soil or sawdust for pupation.

The $3^{\text {rd }}$ instar larva begins to brown and has white lateral stripes. The $4^{\text {th }}$ to $6^{\text {th }}$ instar larvae are larger in size, have clearer lateral stripes on the lateral side, and visible "Y" form on the head. In addition, also the pinacula in the last abdomen is clearly visible forming a square pattern and forming a trapezoid pattern on the previous abdomen. The $6^{\text {th }}$ instar larva is shrunk before pupation.

The male and female $S$. frugiperda pupae can be distinguished by looking at genital opening and anal slot distance of the pupa. The distance of genital and anal slots of male pupae is shorter than females. The color of pupae is brightly reddish-brown (Figure 5). The wing pattern and color can distinguish male and female imago. Male imago has a lighter wing color and has a kidney-like pattern. The wing of the female imago is duller and has no visible pattern.
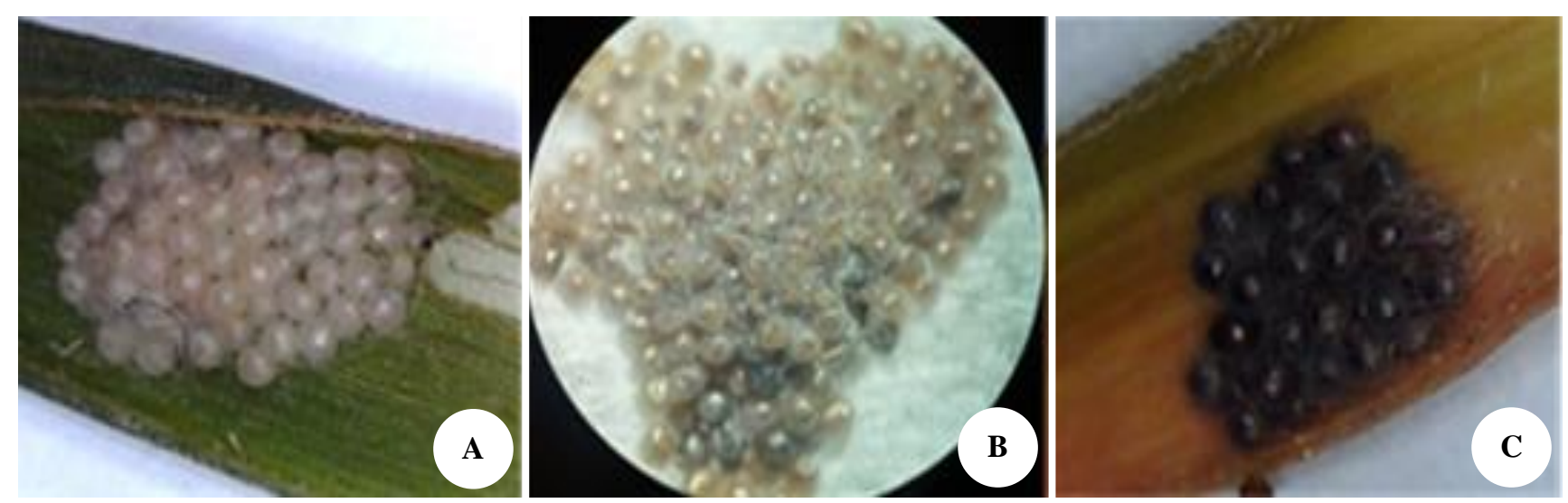

Figure 2. Eggs of S. frugiperda at various ages: A. New oviposited eggs, B. Medium age (one day), C. Hatch immediately 


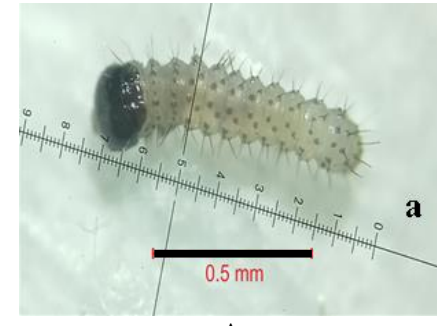

A

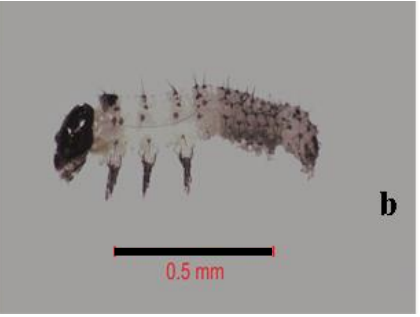

B

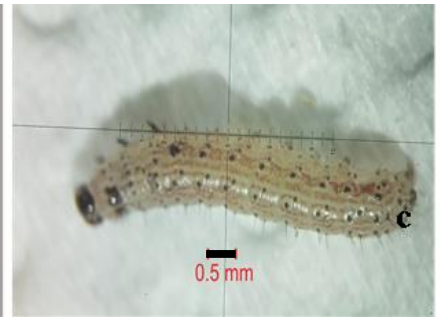

C

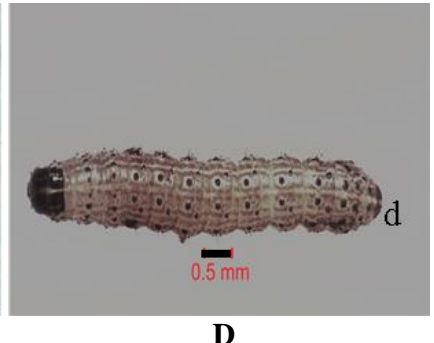

$\mathbf{D}$

Figure 3. Spodoptera frugiperda larvae, A. $1^{\text {st }}$ instar, B. Microscopic $1^{\text {st }}$ instar, C. $2^{\text {nd }}$ instar, and D. Microscopic $2^{\text {nd }}$ instar. Bar $=0.05 \mathrm{~mm}$

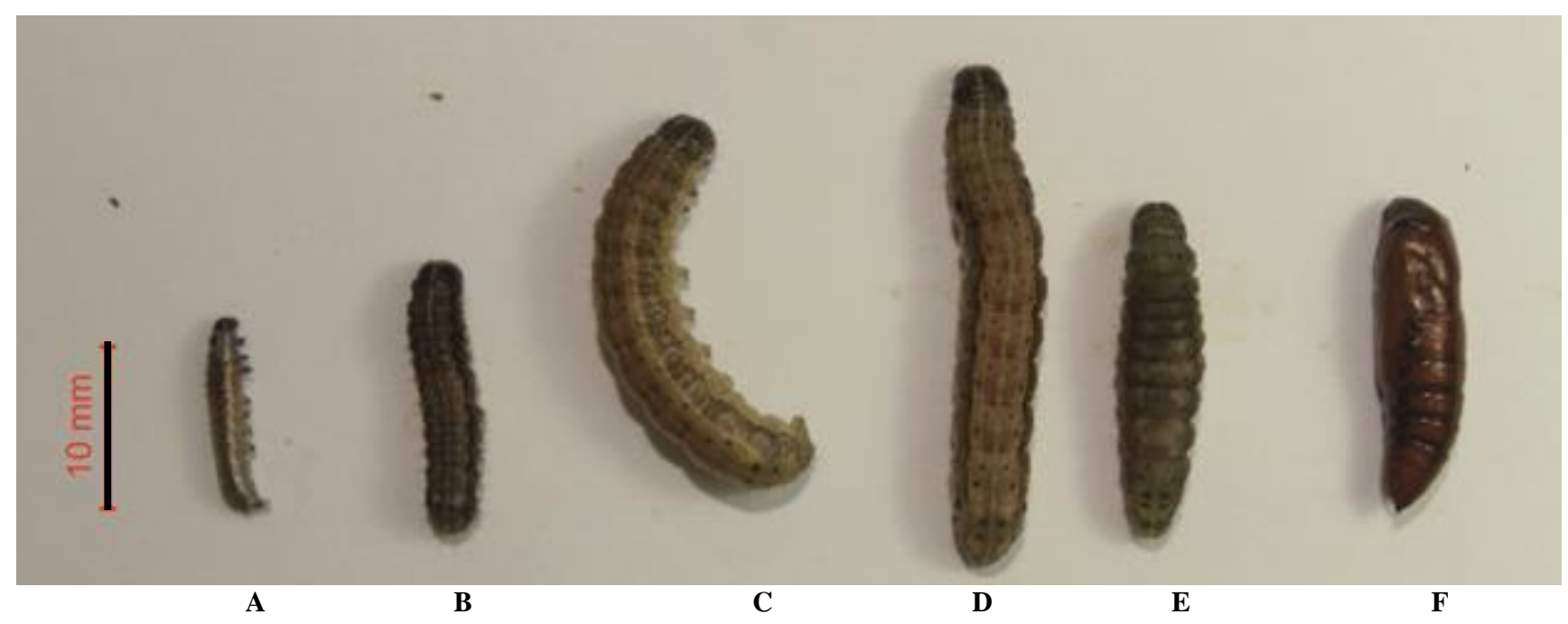

Figure 4. Spodoptera frugiperda larvae and pupa, a) $3^{\text {rd }}$ instar, b) $4^{\text {th }}$ instar, c) $5^{\text {th }}$ instar, d) $6^{\text {th }}$ instar, e) prepupa, and f) pupa
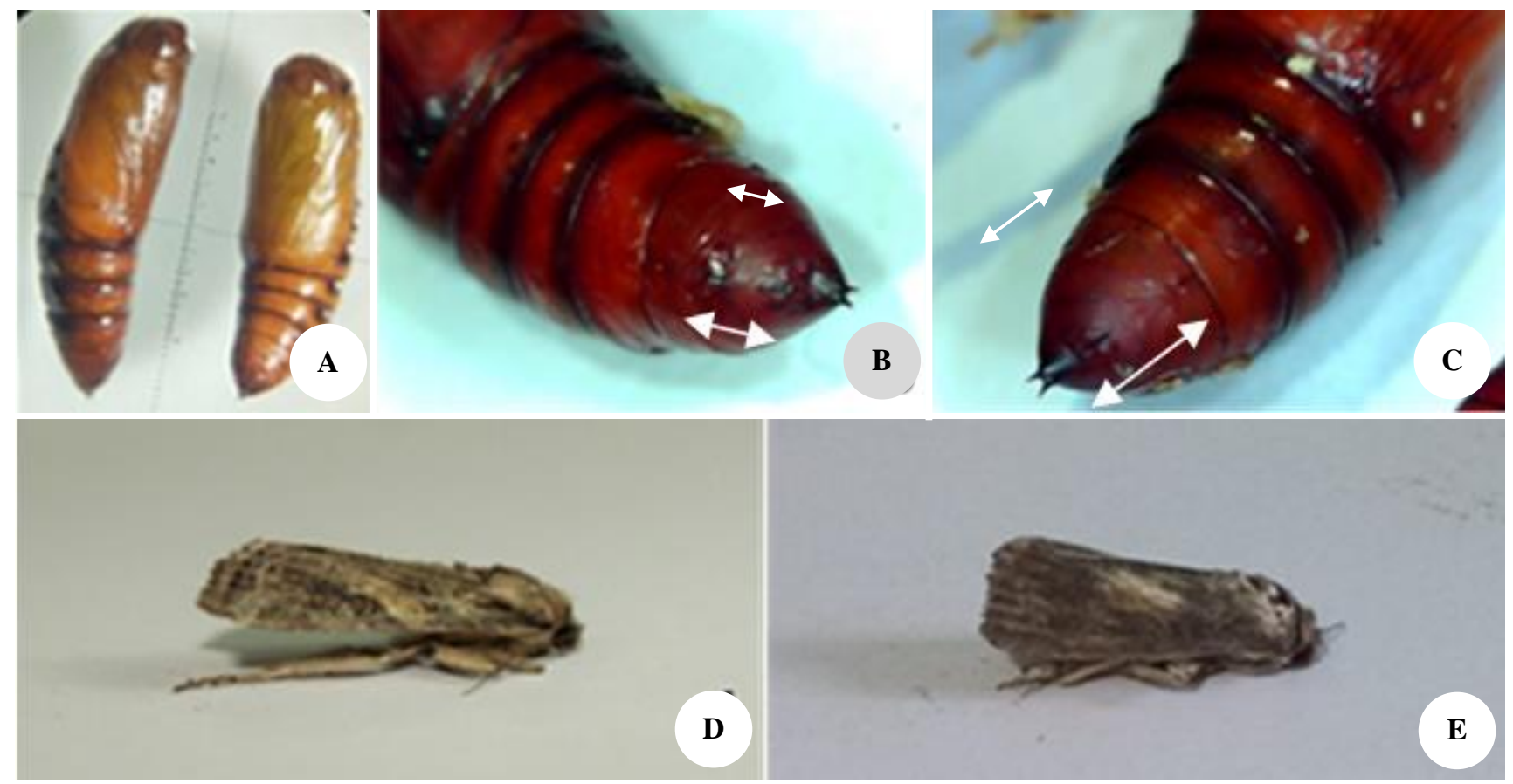

Figure 5. Spodoptera frugiperda pupae and imago: A. Male and female pupae, B. Male pupa (has bigger size), C. Female pupae (the distance between genital and anal farther than male), D. Male imago (the patterns on the wing are more complex), E. Female imago 


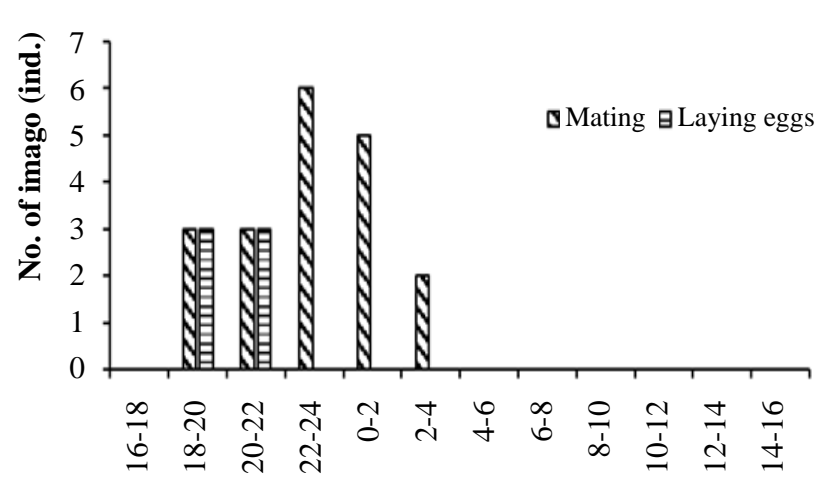

Time

Figure 6. Mating and laying eggs in 24 hours of Spodoptera frugiperda imago

\section{Biology of fall armyworm}

The imago is active in the late afternoon until early morning. Mating behavior takes place from $06.00 \mathrm{pm}$ until $04.00 \mathrm{am}$. After that time there is no more mating imago (Figure 6). The egg-laying occurs from $06.00 \mathrm{pm}$ to 10.00 pm. This is in line with Assefa (2018) that imago of $S$. frugiperda is nocturnal and mating behavior of adult occurs overnight. Another report stated that imago from the Noctuid adults began laying eggs at $07.00 \mathrm{pm}$ until 11.00 pm (Yunus et al. 2011).

The egg stage occurs for two to three days. Eggs that are in a group will hatch on the same day. Hatching of eggs takes place between $10.00 \mathrm{pm}$ until 12.00 am (Figure 7). $35 \%$ of the eggs hatched at 00.00 am to $02.00 \mathrm{am}$. Hatching eggs of at least $5 \%$ occurs between $10.00 \mathrm{pm}$ and $12.00 \mathrm{pm}$ and $08.00 \mathrm{am}-10.00 \mathrm{am}$. Egg hatching did not occur from 14.00 to 22.00 .

The development of male and female larva stage of $1^{\text {st }}$ to $6^{\text {th }}$ instar and the length of life between male and female imago were not significantly different (Table 1). Differences in the development of male and female insects occur in the pupa phase. Male stadium pupal stage is longer than female pupae. This happens because the female insect needs to ripen the eggs first before mating.

There are no significant difference values of life cycle between males and females, except pupa stage (Table 1). Life cycle of FAW is $32.26 \pm 0.41$. Development of larva stage of $1^{\text {st }}$ to $6^{\text {th }}$ instar was \pm 15 days for each female and male. The larva period tends to be about $14-19$ days has been reported (Sharanabasappa et al. 2018). The life cycle of male imago is $10.58 \pm 0.56$ days and $9.53 \pm 0.44$ day in females. According to Wang et al. (2020b), the lifecycle of male imago is $9.09 \pm 1.64$ days and $16.21 \pm 0.1$ days for female imago. The lifecycle of imago can affect the number of population in a life cycle. The longevity of $S$. frugiperda imago causes rapid population growth. Duration of pupa stage in this research was $8.78 \pm 0.12$ for male and $7.81 \pm 0.15$ for female, this accordance with statement of Silva et al. (2017) that longevity of pupa phase of $S$. frugiperda $8.54 \pm 0.09$. Adult longevity male, female and pre-oviposition period range from $10.58 \pm 0.56,9.53 \pm$ 0.44 , and $2.56 \pm 0.45$ days. Fecundity of $S$. frugiperda was

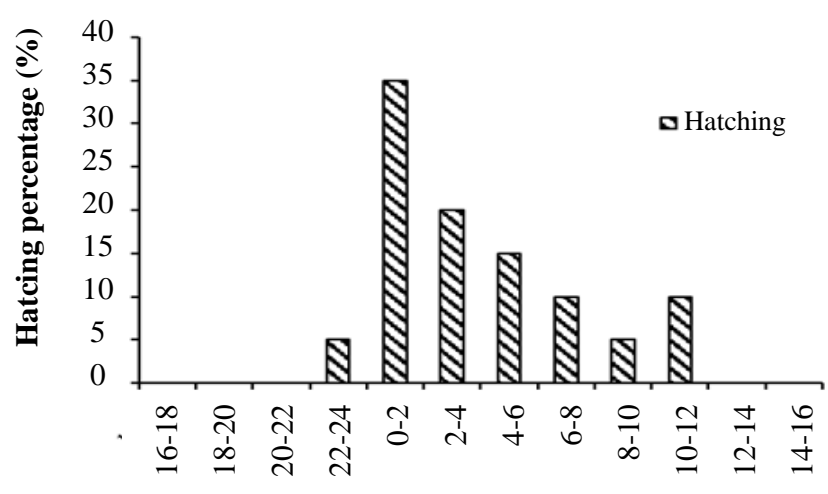

Time

Figure 7. Hatching eggs percentage of Spodoptera frugiperda at the specific time

\section{$1012.62 \pm 99.12$ eggs.}

Observations were carried out until all individuals died, i.e. 39 days. There was a decrease in the chance of survival from day 3 to 6 with significant decrease during 23-29 days. So that, $S$. frugiperda included in the type I survivorship curve. because the highest mortality occurs when the population is getting older and few deaths at the beginning (Figure 8). Similarly, Hutasoit et al. (2020) research states that the chance of survival of $S$. frugiperda decreases when it becomes the $6^{\text {th }}$ instar and pupa.

Laying eggs of S. frugiperda occur on days 28 to 37 . The highest daily average female fecundity occurs on day 29 with 87 eggs and decreased until day 37 (Figure 8). The lifecycle of imago can affect the number of population in a life cycle. The longevity of $S$. frugiperda imago causes rapid population growth and difficulty to control using natural enemies.

The results show that the gross reproductive value (GRR) of $S$. frugiperda is $394.791 \pm 0.455$ individuals per generation. Meanwhile, the reproduction rate (Ro) shows that each generation will double by $104.781 \pm 0.155$ times with the time of life cycle in one generation is $30,114 \pm$ 0.002 days (Table 2). The higher GRR and Ro values indicate the level of suitability of the insect's life to the host (Hidayat et al. 2019).

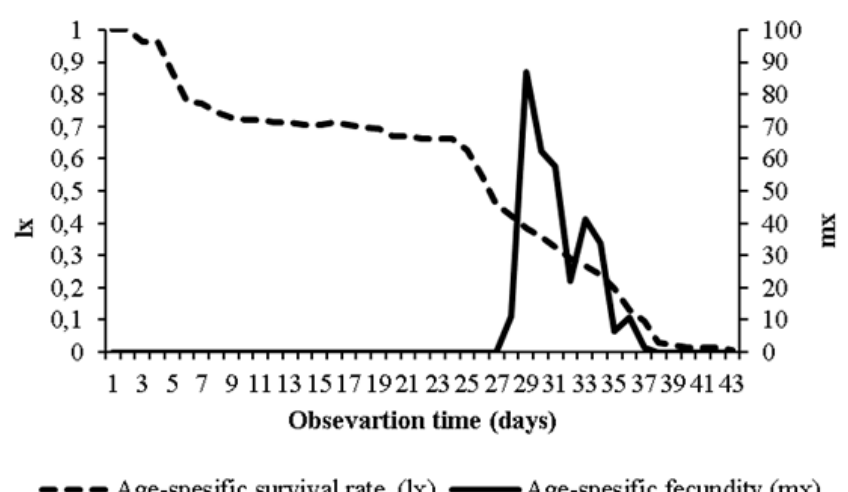

Figure 8. The curve of age-spesific survival rate (lx) and agespesific fecundity (mx) of Spodoptera frugiperda 
Table 1. Development of male and female insects Spodoptera frugiperda

\begin{tabular}{lcccc}
\hline \multicolumn{1}{c}{ Phase } & $\begin{array}{c}\text { Male phase (days) } \\
(\overline{\mathbf{x}} \pm \text { SE) }\end{array}$ & $\begin{array}{c}\text { Number of Individuals } \\
(\mathbf{n})\end{array}$ & $\begin{array}{c}\text { Female phase (days) } \\
(\overline{\mathbf{x}} \pm \text { SE) }\end{array}$ & $\begin{array}{c}\text { Number of } \\
\text { individuals }(\mathbf{n})\end{array}$ \\
\hline Egg & $2.00 \pm 0.00$ & 3760 & $2.00 \pm 0.00$ & 3760 \\
$1^{\text {st } I n s t a r}$ & $3.22 \pm 0.11 \mathrm{a}$ & 42 & $3.10 \pm 0.09 \mathrm{a}$ & 49 \\
$2^{\text {nd }}$ Instar & $2.34 \pm 0.12 \mathrm{a}$ & 42 & $2.29 \pm 0.10 \mathrm{a}$ & 49 \\
$3^{\text {th } I n s t a r}$ & $1.93 \pm 0.05 \mathrm{a}$ & 42 & $2.06 \pm 0.06 \mathrm{a}$ & 49 \\
$4^{\text {th }}$ Instar & $2.27 \pm 0.08 \mathrm{a}$ & 42 & $2.12 \pm 0.05 \mathrm{a}$ & 49 \\
$5^{\text {th } I n s t a r}$ & $2.17 \pm 0.10 \mathrm{a}$ & 42 & $2.02 \pm 0.08 \mathrm{a}$ & 49 \\
$6^{\text {th } I n s t a r}$ & $3.44 \pm 0.14 \mathrm{a}$ & 42 & $3.33 \pm 0.10 \mathrm{a}$ & 49 \\
Pupa & $8.78 \pm 0.12 \mathrm{a}$ & 42 & $7.81 \pm 0.15 \mathrm{~b}$ & 49 \\
Adult longevity & $10.58 \pm 0.56 \mathrm{a}$ & 42 & $9.53 \pm 0.44 \mathrm{a}$ & 49 \\
Life cycle & - & - & $32.26 \pm 0.41$ & 26 \\
Pre-oviposition & - & - & $2.56 \pm 0.45$ & 26 \\
Fecundity & - & - & $1012.62 \pm 99.12$ & 26 \\
\hline
\end{tabular}

Note: Numbers on the same line that are followed by the same letter indicates does not significantly different based on $t$ test, $\alpha=0.05$

Table 2. Demographic statistics of Spodoptera frugiperda

\begin{tabular}{|c|c|c|}
\hline Parameters of population & Mean \pm SE & Unit \\
\hline $\begin{array}{l}\text { Gross reproduction rate } \\
\text { (GRR) }\end{array}$ & $394.791 \pm 0.455$ & $\begin{array}{l}\text { Individual/ } \\
\text { generation }\end{array}$ \\
\hline Net reproduction rate (Ro) & $104.781 \pm 0.155$ & $\begin{array}{l}\text { Individual/ } \\
\text { parent/generation }\end{array}$ \\
\hline Intrinsic rate of increase (r) & $0.154 \pm 0.001$ & $\begin{array}{l}\text { Individual/ } \\
\text { parent/days }\end{array}$ \\
\hline $\begin{array}{l}\text { Generation time average } \\
\text { (T) }\end{array}$ & $30.114 \pm 0.002$ & Days \\
\hline Doubling time (DT) & $4.487 \pm 0.001$ & Days \\
\hline
\end{tabular}

The value of the intrinsic rate of increase (r) of $S$. frugiperda is $0.154 \pm 0.001$ individuals per adult per day. The generation time average (T) of $S$. frugiperda is 30.114 \pm 0.002 days. The doubling time value (DT) of $S$. frugiperda is $4.487 \pm 0.001$ days (Table 2 ). The smaller $\mathrm{T}$ and DT values indicate that the insects will reproduce and multiply faster.

Spodoptera frugiperda can occur in three generations in a maize growing season ( \pm 90 days). The multiple of each generation is $104.781 \pm 0.155$ times the previous generation. It means that if there were 10 larvae at the beginning of the planting season, then in one growing season the maize would be 11 million larvae (Table 2).

\section{REFERENCES}

Assefa F. 2018. Status of Fall armyworm (Spodoptera frugiperda), biology and control measures on maize crop in Ethiopia: A review. J Entomol Res 6(2): 75-85. DOI: 10.33687/entomol.006.02.2498.

Begon M, Townsend CR, Herper JL. 2008. Ecology: From Individuals to Ecosystems. 4th edition. Blackwell Publishing, Oxford, UK.

Birch LC. 1948. The intrinsic rate of natural increase of an insect population. J Anim Ecol 17(1):15-28. DOI: 10.2307/1605.

CABI (Centre for Agriculture and Bioscience International). 2017. Fall Armyworm: Impacts and Implications for Africa [Internet]. Wallingford: CABI; [accessed 2020 Jul 22]. Available at: https://www.cabi.org/cabipublications/fall-armyworm-impacts-and implications-for-africa-2/.
Day R, Abrahams P, Bateman M, Beale T, Clottey V, Cock M, Colmenarez Y, Corniani N, Early R, Godwin J, et al. 2017. Fall armyworm: Impacts and implications for Africa. Outlooks Pest Manag 28(5): 196-201. DOI: 10.1564/v28_oct_02.

Efron B. 1982. The Jackknife, the Bootstrap, and Other Resampling Plans. DOI: 10.1137/1.9781611970319. [Philadelphia]

FAO (Food and Agriculture Organization of the United Nations). 2020. The Global for Fall Armyworm Control; Action Framework 20202022. Rome. [Italy]

Goergen G, Kumar PL, Sankung SB, Togola A, Tamò M. 2016. First report of outbreaks of the Fall armyworm Spodoptera frugiperda (JE Smith) (Lepidoptera, Noctuidae), a new alien invasive pest in West and Central Africa. PLoS ONE 11(10): e0165632. DOI:10.1371/journal. pone.0165632.

Hidayat P, Harleni, Maharani Y, Triwidodo H. 2019. Biology and demography statistic aphids Rhopalosiphum rufabdominale (Sasaki) and Tetraneura nigriabdominalis (Sasaki) (Hemiptera: Aphididae) in rice roots. Indon $\mathrm{J}$ Entomol 16 (3): 180-186. DOI: 10.5994/jei.16.3.180. [Indonesian]

Hutasoit RT, Kalqutny SH, Widiarta IN. 2020. Spatial distribution pattern, bionomic, and demographic parameters of a new invasive species of armyworm Spodoptera frugiperda (Lepidoptera: Noctuidae) in maize of South Sumatera, Indonesia. Biodiversitas 21(8): 3576-3582. DOI: 10.13057/biodiv/d210821.

Maharani Y, Dewi VK, Puspasari LT, Rizkie L, Hidayat Y, Dono D. 2019. Cases of Fall armyworm Spodoptera frugiperda J.E. Smith (Lepidoptera: Noctuidae) attack on maize in Bandung, Garut, and Sumedang District, West Java. Cropsaver 2(1): 38-46. DOI: 10.24198/cropsaver.v2i1.23013.

Montezano DG, Specht A, Sosa-Gómez DR, Roque-Specht VF, SousaSilva JC, Paula-Moraes SVD, Peterson JA, Hunt T. 2018. Host plants of Spodoptera frugiperda (Lepidoptera: Noctuidae) in the Americas. Afr Entomol 26 (2): 286-300. DOI: 10.4001/003.026.0286.

Nagoshi RN, Meagher RL. 2004. Seasonal distribution of Fall armyworm (Lepidoptera: Noctuidae) host strains in agricultural and turfgrass habitats. Environ Entomol 33(4): 881-889. DOI: 10.1603/0046-225X33.4.881.

Sartiami D, Dadang, Harahap IS, Kusumah YM, Anwar R. 2020. First record of Fall armyworm (Spodoptera frugiperda) in Indonesia and its occurrence in three provinces. IOP Conf Ser Earth Environ Sci 468: 012021. DOI: 10.1088/1755-1315/468/1/012021.

Sharanabasappa, Kalleshwaraswamy CM, Maruthi MS, Pavithra HB. 2018. Biology of invasive worm Spodoptera frugiperda (J.E. Smith) (Lepidoptera: Noctuidae) on maize. Indian J Entomol 80(3): 540-543. DOI: $10.5958 / 0974-8172.2018 .00238 .9$

Silva DMD, Bueno ADF, Andrade K, Stecca CDS, Neves PMOJ, Oliveira MCND. 2017. Biology and nutrition of Spodoptera frugiperda (Lepidoptera: Noctuidae) fed on different food sources. Sci Agric 7(1): 18-31. DOI: 10.1590/1678-992X-2015-0160.

Sparks AN. 1979. A review of the biology of the Fall armyworm. Fla Entomol 62(2): 82-87. DOI: 10.2307/3494083. 
Wang R, Jiang C, Guo X, Chen D, You C, Zhang Y, Yang M, Li Q. 2020a. Potential distribution of Spodoptera frugiperda (J.E. Smith) in China and the major factor influencing distribution. Glob Ecol Conserv 20: e00865. DOI: 10.1016/j.gecco.2019.e00865.

Wang W, He P, Zhang Y, Liu T, Jing X, Zhang S. 2020b. The population growth of Spodoptera frugiperda on six cash crop species and implications for its occurrence and damage potential in China. Insect 11: 2-14. DOI: 10.3390/insects11090639.

Yunus M, Martono A, Wijonarko A, Soesilohadi RCH. 2011. The activities of Scirpophaga incertulas adult from Klaten regency. J Perlindungan Tanaman Indonesia 17 (1): 18-25. DOI: 10.22146/jpti.9389. [Indonesian] 